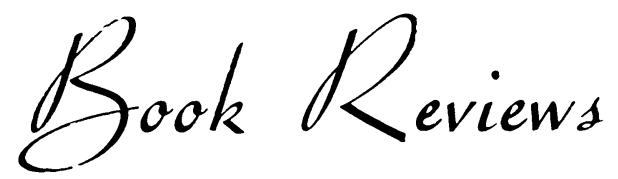

\section{OPERATIVE SURGERY}

\section{Volume V-Orthopaedic Surgery}

Edited by Charles Rob, M.C., M.Chir., F.R.C.S. and Rodney Smith, M.S., F.R.C.S. Pp. xiii $+366+$ index 5 , fully illustrated. London: Butterworth \& Co. Ltd. I957. £5 ros.

This volume maintains the uniformly high standard of its predecessors, both in its descriptions of specific orthopaedic operations and in its chapters on general principles. These chapters on methods of treatment in general are particularly useful in that they give a succinct presentation of procedures which in many books are either spread over many chapters or discussed so briefly as to be of no practical value. The choice of methods of traction for example often seems to the Fellowship candidate to be a matter of deep incomprehensible mystery but in this volume such methods are summarized collectively in an excellent chapter by Osmund Clarke and Crawford Adams. A similar chapter on surgical exposures in the limbs might perhaps be an equally valuable addition to this series.

A good example of the sane balance of the book is the way in which operations for recurrent dislocation of the shoulder are described. The Patti-Platt operation, probably the operation now used most widely, is described in detail and is followed by a short summary of the Bankart, Nicola and boneblock operations.

This book is recommended as strongly as the previous volumes and should be of great value to practising surgeons and candidates for the higher examinations.

\section{MYTH AND GUILT}

By Theodor Reik. Pp. 335. London: Hutchinson \& Co. Ltd. $\quad$ I $958 . \quad 25$ s.

Geneticists tell us that we have all been physically represented in some 2 million generations of bodies -a line of physical existence which takes us back to the first man. Theologians (with original Sin) and psychologists (with Group Mind) have parallel convictions.

In this search for a comprehensive truth, the author-one of Freud's earliest and most brilliant pupils-uses psycho-analytic material supported by evidence from scriptural and anthropological sources to provide an explanation of collective guilt and the myth of Adam's Fall. 'This is an exhaustive study of many related religious beliefs, especially those concerned with the Passion of Christ, and the author concludes that man's sense of guilt stems from pre-history and is perpetuated by natural pride. Inevitably this leads to a pessimistic view of humanity, and the author's concluding words: ' we are all potential murderers,' might well be the sub-title of the book.

Interesting though these hypotheses are to theology and psycho-analytic theory, their clinical value is relatively small. Nevertheless, this is a very readable book devoid of esoteric jargon which cannot but give the reader a deeper understanding man of hufeelings.

L.R.C.H.

\section{HOMOSEXUALITY}

\section{Its Nature, Causation and Treatment}

By Cilfford Allen, M.D., M.R.C.P., D.P.M.

Pp. 143. London: Staples Press Ltd. $195^{8}$. I 5 s.

The publication of the Wolfenden Report some months ago revived interest in homosexuality, even if it disappointed the many who are seriously, concerned about this socio-medical problem. Sex in any of its forms touches the basic roots of our emotionality, and unless we have been trained to recognize our own intrapersonal involvement, it is impossible for us to take a strictly objective and impartial view of sexual behaviour. Thus it is to the medical, rather than the legal, profession that we must look for any genuine improvement of approach to these social deviates.

Dr. Allen has studied the problem of sexual abnormality for several decades. He has been intimately connected with the clinical problems long enough to see many optimistic therapies fail, and many judicial modes of handling offenders turn them from disturbed deviants into asocial recidivists. In this book he discusses the incidence, cause, social significance, and prevention and treatment of homosexuality, and in a concluding chapter gives a very thoughtful analysis of the Wolfenden Report. The author's standpoint is that homosexuality is a psychogenic disease which 
will yield to psychotherapeutic treatment in much the same way as does a neurosis. Rejecting all types of physical treatment, he cites some two dozen cases of his own in which the cures are said to be due to psychotherapy alone. Lacking the validity of controlled therapeutic trials, these nevertheless can be welcomed as a precise and positive approach to a difficult and every-present problem, and this sympathetic optimistic work should be read by all who have to deal with the homosexual.

\section{L.R.C.H.}

\section{AORTOGRAPHY}

By W. Barr StIRling, Ch.M., F.R.C.S. F.R.F.P.S.G. Pp. vii +292 , with 155 illustrations. Edinburgh: E. \& S. Livingstone Ltd. 1957. 5os.

This small book on aortography is based on a personal experience of some 500 lumbar aortograms performed mainly for the diagnosis and management of various renal conditions. Some of the work is taken from a Thesis submitted to the University of Glasgow for the degree of Ch.M.

This work describes the technique for aortography used by the author in Glasgow. This differs little in basic principles from that generally used at other centres throughout the country. However, the technique as described recommends concentrations of contrast medium higher than those now generally considered acceptable. It is also surprising that the author does not recommend test doses or other means for localizing the needle point and preventing the injection of the whole dose of contrast medium into a single renal artery or other branch of the aorta.

The section on the hazards and complications of aortography makes no mention of anuria, from which a large number of deaths have been recorded. Other serious and well recognized complications such as paraplegia are also inadequately dealt with.

The precautions to be taken against radiation danger are glossed over in a single sentence, which is rather alarming in a book primarily written for urologists and not radiologists. The protection shown on the single photograph illustrating this aspect is quite inadequate. If more adequate protection is in fact used, then this should be made clear.

Although the title of this book is 'Aortography' it deals only with lumbar aortography. Aortography by percutaneous catheterization, which is now well established as a valuable, and in some cases essential, mode of investigation, is rather casually. dismissed as are other newer techniques, such as cine radiography and selective renal catheterization. The latter technique is not even mentioned.

The main part of the book consists of illustrative case reports taken from the author's material. As might be expected, these refer mainly to renal conditions, though there are a few examples of vascular lesions of the aorta and its main branches included in a small chapter at the end of the book.
It is clear from the above criticisms that those with practical experience of the difficulties and problems $\frac{2}{\tau}$ of aortography will find much to disagree with in this book. Nevertheless it represents a good $\frac{\varrho}{C}$ account of the possibilities of lumbar aortography in the field of urology and places on record a valuable personal experience.

D.S.

\section{CLINICAL NEUROSURGERY}

Proceedings of the Congress of Neurological Surgeons, Los Angeles, California. Pp. xiv + 。 26I, with I 3 I illustrations. London: Baillière, Tindall and Cox. 1957. \$10.00.

Professor Carl Rand was the guest of honour at 8 this Congress, and in this book are three valuable contributions by him, (i) on his personal experiences of pituitary tumours and (ii) on his studies of the histological changes in the brain consequent to $\omega_{0}$ head injuries. Later, there are excellent accounts of the symposia held at Los Angeles on (i) carotid $\infty$ artery thrombosis, (ii) unconsciousness and (iii) the uses of hyperthermia and hibernation in neurosurgery.

The book is excellently illustrated and the wealth of up-to-date information it contains makes lucid reading. It is primarily for the neurological specialist (whether physician or surgeon) and fog research workers in the neurological field. The of section on the carotid artery, however, is short and comprehensive, and will be of interest to vascula surgeons.

\section{D.L.B.F}

\section{PAEDIATRICS FOR THE PRACTITIONER Supplement 1957}

Edited by W. GaISFord, M.D., M.Sc., F.R.C.P., and R. Lightwood, M.D., F.R.C.P., D.P.H. Pp. v +157 , index 8, with 45 illustrations. London: Butterworth \& Co. Ltd. 1957. 35s.

This second annual supplement contains new chapters on gamma-globulins and immunity, prophylactic immunization, use of ACTH, cortisone and its derivatives, tuberculosis of the skin and mucous membranes, congenital heart disease, galactosaemia, funnel chest, cysts and sinuses in the neck, and diseases and anomalies of the testes and penis.

Particularly valuable are the chapters on gammaglobulins, which makes available much information until now only recorded in specialist journals, and on prophylactic immunization, which will enable the practitioner to answer most parents' queries.

The chapter on the use of ACTH and cortisone is commendably short; they are not drugs ordinarily to be used in general practice except following specialist advice. There is no mention of the local use of hydrocortisone in skin conditions.

The chapter on funnel chest does not make it

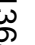

